\title{
Kleptomania like Features in a Case of Schizophrenia following Age-related Cortical Atrophy
}

\author{
${ }^{1}$ Shorouq Motwani, ${ }^{2}$ Sagar Karia, ${ }^{3}$ Nilesh Shah, ${ }^{4}$ Avinash De Sousa
}

\begin{abstract}
Kleptomania is a disorder of impulse control characterized by the impulse to steal objects that are not of much personal use or monetary value and the inability to control that impulse. Though there is a dearth of imaging studies of kleptomania, the literature suggests thatdamage of the orbitofrontal cortex and the orbitofrontal subcortical circuits may be implicated in kleptomania. The following case report presents a case of schizophrenia that developed frontal lobe ischemic changes with age resulting in the genesis of kleptomania like symptoms.
\end{abstract}

Keywords: Frontal lobe damage, Kleptomania, Orbitofrontal cortex, Schizophrenia

How to cite this article: Motwani S, Karia S, Shah N, Sousa AD. Kleptomania like Features in a Case of Schizophrenia following Age-related Cortical Atrophy. Ind J Priv Psychiatry 2018;12(1):31-33.

\section{Source of support: Nil}

\section{Conflict of interest: None}

\section{INTRODUCTION}

Kleptomania is an impulse control disorder characterized by the impulse to steal objects not needed for personal use or of poor monetary value and an inability to control that impulse. ${ }^{1}$ There are no detailed brain-imaging studies of patients who suffer from kleptomania, but research literature suggests that damage to orbitofrontal-subcortical circuits may result in kleptomania. ${ }^{2}$ Kleptomania like features have been reported in patients with schizophrenia ${ }^{3}$ and patients with frontotemporal damage. ${ }^{4}$ The orbitofrontal cortex of the brain is the center for behavioral regulation and decision making and hence has been implicated in disorders of impulse control like kleptomania. ${ }^{5}$ We present herewith a case of schizophrenia who developed age-related cortical atrophy and frontal lobe ischemic changes that resulted in kleptomania like symptoms.

\footnotetext{
${ }^{1}$ Resident Doctor, ${ }^{2}$ Assistant Professor, ${ }^{3}$ Professor and Head, ${ }^{4}$ Research Associate

${ }^{1-4}$ Department of Psychiatry, Lokmanya Tilak Municipal Medical College, Mumbai, India
}

Corresponding Author: Avinash De Sousa, Research Associate, Department of Psychiatry, Lokmanya Tilak Municipal Medical College, Mumbai, India, Phone: 919820696828. e-mail: avinashdes888@gmail.com

\section{CASE REPORT}

A 54-year-old married, Hindu, right-handed illiterate woman working as a house help and speaking Marathi and Hindi, residing at Mumbai, was brought by her daughter with chief complaints of forgetfulness and decreased alertness in her daily activities since the past 7 months. The lady was a known case of paranoid schizophrenia who had been suffering from the disorder since the past 10 years. The patient was apparently alright till around 10 years ago when after certain financial constraints, she had to sell her family home. She was also suffering from hyperthyroidism at that time and was not compliant with her medications. Around this time, her family members noticed that she was becoming irritable about trivial issues. She suspected her husband of having an extramarital affair and followed him around. She believed that her husband offered to buy groceries because he was having an affair with the shopkeeper. She also suspected that someone had placed cameras all over her house to watch her and her family and she would turn off all the light bulbs in the bathroom before going for a bath so that the cameras could not capture her. She would not allow her children to venture outside the house because she feared that someone would kidnap and kill them. If they did go out in spite of her apprehension, she would become angry, abusive and assaultive towards them. She claimed that she could see blood spilled all over her house which was invisible to others and she would ask her family members to leave the house when she saw the blood, claiming that they would be killed soon.

The patient would also hear someone's voice talking to her, which was in audible to other family members. She did not mention the details about these voices but claimed that they were threatening to kill her. She was often seen to be muttering, gesticulating and crying by herself. She was particularly suspicious of her neighbor with whom she had frequent altercations and believed that he was jealous of her and was trying to harass her by cutting off electricity supply to her house.

She often ran away from her house after minor altercations with her family members and would either go to one of her relatives or wander on the road and had to be brought back by her family members. Her sleep 
was disturbed, and her appetite had reduced, and she would spit or vomit out her food with gradual significant weight loss. Her self-care had deteriorated, and she had to be forcefully bathed, or someone had to brush her teeth.

In 2010, she was brought to the emergency department of our hospital because she had stopped eating completely and would be seen scratching the floor in a fearful state claiming that her family would be killed. She was admitted for 15 days and started on medications, given a course of electroconvulsive therapy and discharged on medication.

She maintained well on medication (risperidone $2 \mathrm{mg}$ per day, olanzapine $10 \mathrm{mg}$ at night and trihexyphenidyl 2 mg per day) till January 2018 when her family members noticed that she would bring home things like chips or biscuits from the local grocery store, but would not consume them. They later learned that she had stolen them from the grocery store when the shopkeeper was not watching. When asked about it, she would initially deny it but later claim that she could not control herself and would steal whatever was easily accessible. She would do this at any store or fruit vendor she was at and stole things she did not even need. Three months later, she was once caught stealing by a fruit vendor who threatened to turn her to the police. Since January 2018, her daughter also reported that she had started forgetting things like where she had kept her belongings or what she had eaten a few hours earlier. The daughter also reported that she did not seem as alert as before and took some time to respond to things like switching off the fire supply to boiling water.

There was no history suggestive of depressive features, bipolar mood disorder (BMD), conduct features, antisocial personality, substance use, obsessive-compulsive features, phobia, seizuresorhead injury. She was aknown case of Hyperthyroidism for the last 10 years, on tablet carbimazole $5 \mathrm{mg}$ twice a day. She had a history of stillbirth oftwins in 1981 with probable post-partum hemorrhage followed by a history of left-sided hemiparesis (which had recovered fully) and facial palsy (which had also recovered). Her current thyroid profile when investigated was within normal limits.

Neuroimaging in the form of magnetic resonance imaging of the brain was done in May 2018 and showed T2 FLAIR hyperintense foci in the bilateral frontal subcortical white matter and centrum semiovale suggestive of chronic ischemic changes and mild age-related cerebral atrophy. The score on the mini-mental state examination was $26 / 30$. The details of birth and developmental history were not available. The family history of mental illness with a history of suicide in her sister was noted.
Premorbidly, she was reported to have an extrovert personality, and she was short tempered.

On mental state examination (MSE), the patient was conscious, cooperative, oriented to time, place and person. Rapport could be established, and she initiated and maintained eye to eye contact. Attention was arousable and sustained. Her mood was cheerful and appropriate to the surroundings. Her speech was continuous, coherent, relevant with normal rate and volume. No delusions were present. No hallucinations were reported. No formal disorders of thought could be elicited. Memory testing revealed that immediate memory was fine, recent memory was impaired, and remote memory was intact. Concepts were intact, and test judgment was intact. Insight into the illness was present. On being asked about the kleptomania like features, the patient mentioned that she had a strong urge to do the same and felt anxiety before the act which was relieved on completing the act. Escitalopram $10 \mathrm{mg}$ at night was added to her medication, and she was started on piracetam $800 \mathrm{mg}$ thrice a day because of memory impairment. She reported a reduction by $80 \%$ in her kleptomania like behavior and improvement in memory on weekly follow-ups over the next one month.

\section{DISCUSSION}

The following patient probably showed signs of kleptomania following damage to the frontal lobes and orbitofrontal cortex. There is ahypothesis that the inferior frontal region of the brain is involved in impulsive behaviors that involve poor decision-making and stealing unnecessary items. ${ }^{6}$ Kleptomania patients score high on tests of impulsivity and shoplifting reflects an inability to control thedesire for immediate reward due to damage to prefrontal functions. ${ }^{7}$ There may also be an impaired connectivity in the tracts running from the limbic region to the thalamus and the prefrontal region. ${ }^{8}$ These findings may have implications when these symptoms are seen in patients with dementia and may help explain the complete neurobiology of kleptomania. This may also have legal implications though further research in this area is warranted.

\section{REFERENCES}

1. Kirsch JL, Simeon D, Berlin H, Hollander E. Disruptive, Impulse Control, and Conduct Disorders: Intermittent Explosive Disorder, Kleptomania, and Pyromania. Psychiatry 2015;1:1367-1393.

2. Bechara A, Damasio H, Damasio AR. Emotion, decision making and the orbitofrontal cortex. Cerebral Cortex 2000;10(3):295-307.

3. Chong SA. Schizophrenia and kleptomania: a case report--a biological link?. Ann Acad Med Singapore 1995;24(6):860-862. 
4. Mendez MF. Pathological stealing in dementia: poor response to SSRI medications. J Clin Psychiatry 2011;72(3):418-419.

5. Wallis JD. Orbitofrontal cortex and its contribution to decisionmaking. Ann Rev Neurosci 2007;30:31-56.

6. Bechara A. The role of emotion in decision-making: evidence from neurological patients with orbitofrontal damage. Brain Cogn 2004;55(1):30-40.
7. Grant JE, Kim SW. Clinical characteristics and associated psychopathology of 22 patients with kleptomania. Compr Psychiatry 2002;43(5):378-384.

8. Denburg NL, Cole CA, Hernandez M, Yamada TH, Tranel D, Bechara A, Wallace RB. The orbitofrontal cortex, realworld decision making, and normal aging. Ann NY Acad Sci 2007;1121(1):480-498. 